\title{
IbM Pelatihan, Pembinaan dan Pendampingan Penggunaan Aplikasi Management Stock Control
}

\author{
Muhammad Wali ${ }^{1}$, Ismail ${ }^{*}$, Taufiq Iqbal ${ }^{3}$, Jhony Syafwandhinata 4 \\ 1,2,3,4 Program Studi Manajemen Informatika, Fakultas Ilmu Komputer, AMIK Indonesia, Jl. T. \\ Nyak Arief No. 400, Kota Banda Aceh, Provinsi Aceh, Indonesia \\ Corresponding Email: ismail@amikindonesia.ac.id 2.
}

\section{Article History:}

Received: Nov 17th 2020

Revised: Jan 24th 2021

Accepted: Apr 23th 2021

Keywords: Community Service Activities; Training; Coaching; Accompaniment; Application; Management Stock Control.
Abstract: The purpose of this service activity is to provide Training, Coaching, and Assistance for Stock Control Management Applications and it is hoped that the participants can; 1) Understand the strategy for the supply of goods, 2) Understand and be able to control spare parts, 3) Be able to provide the goods needed in the remodeling process, 4) $\mathrm{Be}$ able to manage spare parts efficiently and be able to apply methods Determine the level of reordering and minimum inventory for inventory optimization, and 5) Evaluating the material planning system that has been running so that we can find out the core of the problems faced and how to solve them. The method of implementing the program to be carried out is; 1 ) Presentation, 2) Experience Sharing Discussion, 3) Training (Training for Users), and 4) Further assistance in the use of the application. This Community Service Implementation Activity was held for 4 (four) months from early December 2019 to the end of March 2020. This activity was attended by all personnel of Gober Indo's local business partners. Based on the results of the activities that have been carried out, several conclusions can be drawn, namely; 1) The development of a web-based Stock Control Management application has been successfully built, 2) Assistance and training activities for the use of the appropriate Stock Control Management Application and can help partners, 3) Service activities that are followed very enthusiastically, It can be seen that many members and owners have attended the training, and 4) Supporting activities for the Stock Control Management Application are expected to continue with the development of partner business finances. 


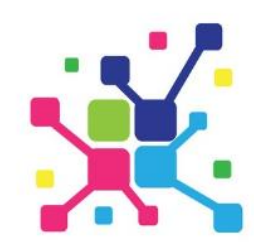

\section{Pendahuluan}

Management Stock Control adalah salah satu aspek terpenting dalam menjalankan bisnis $[1,2]$. Bisa dikatakan, manajemen persediaan merupakan jalur kehidupan bisnis sebuah perusahaan industry [2,3]. Kelebihan persediaan merupakan pemborosan karena menyebabkan biaya penyimpanan dan pemeliharaan yang terlalu tinggi selama penyimpanan di Gudang [4,5]. Pelaku usaha menambah nilai pada produk yang mereka tangani dengan mendekatkan mereka ke konsumen akhir [6,7]. Dalam hal ini, pengendalian tingkat stok yang efektif merupakan ukuran penting dari kinerja operasional $[8,9]$, terutama dalam konteks pencapaian layanan pelanggan tingkat tinggi $[10,11]$.

Meningkatnya kebutuhan perusahaan dengan berbagai jenis barang yang diperlukan [12], membuat banyak perusahaan meninjau kembali strategi inventory mereka. Salah satu fungsi utama dalam pengaturan inventory adalah perencanaan kebutuhan material $[13,14]$, dimana fungsi ini bertujuan untuk merencanakan berapa banyak dan kapan material dibutuhkan pada tingkat biaya yang optimum [15]. Untuk mendukung keputusan tersebut harus ditentukan terlebih dahulu jumlah minimum inventory yang ada dalam gudang dan reorder level masing-masing material [16, 17]. Perhitungan ini membutuhkan kecermatan karena dipengaruhi oleh banyak faktor antara lain fluktuasi tingkat pemakaian, fluktuasi lead time pengadaan dan service level yang diinginkan $[18,15,12]$. Kegiatan pengabdian ini akan membahas management dan inventory control termasuk latihan dalam mengaplikasikan aplikasi Management Stock Control untuk menentukan reorder level dan minimum stock dengan mempertimbangkan berbagai faktor tersebut.

Salah satu bisnis yang banyaknya kegiatan management dan inventory control adalah Gober Indo, UMKM lokal ini bergerak pada bidang konveksi dimana memproduksi T-Shirt, Jersey, Print Baju, Sablon, Bordir dan lain sebagainya yang memiliki bahan baku yang banyak. Permasalahan terjadi ketika order semakin tinggi tetapi pemilik belum membuat keputusan yang tepat dan akurat untuk menentukan berapa banyak barang yang dipesan ke supplier untuk pengisian stok.

Tujuan Pelatihan, Pembinaan dan Pendampingan yang dilakukan agar mitra dapat; 1) Memahami strategi penyediaan barang, 2) Memahami dan mampu melakukan pengendalian suku cadang, 3) Mampu menyediakan barang yang diperlukan dalam proses overhaul, 4) Mampu mengelola suku cadang dengan efisien dan dapat mengaplikasikan metode untuk menetukan reorder level dan minimum stock untuk optimasi persediaan, dan 5) Melakukan evaluasi terhadap sistem perencanaan material yang selama ini berjalan sehingga bisa diketahui inti masalah yang dihadapi dan cara pemecahannya. 


\section{Metode}

a. Metode Pelaksanaan Kegiatan

Metode pelaksanaan program yang akan dilakukan adalah; 1) Presentasi, 2) Diskusi Sharing Pengalaman, 3) Pelatihan (Training Users), dan 4) Pendampingan lebih lanjut penggunaan aplikasi. Pada metode tahapan persentasi merupakan kegiatan pengajuan suatu topik permasalah yang dihadapi, pendapat atau informasi kepada peserta dan dilanjutkan dengan para peserta saling berbagi pengalaman hasil studi lapangan yang telah dijalankan selama proses manajemen pengendalian stok yang dilakukan saat ini. Pada tahap pelatihan peserta akan diberikan instruksi penggunaan aplikasi, pada tahap akhir pendampingan diberikan kepada peserta untuk melihat serta sebagai evaluasi dari pelatihan serta kegiatan pendampingan.

b. Waktu Efektif Pelaksanaan Kegiatan

Kegiatan Pelaksanaan Pengabdian Kepada Masyarakat ini dilakukan selama 4 (empat) bulan pada awal Desember 2019 sampai dengan akhir Maret 2020. Kegiatan ini dihadiri oleh semua personil mitra usaha lokal Gober Indo.

c. Tempat Kegiatan

Lokasi pengabdian ini dilaksanakan pada ruang atau tempat usaha Gober Indo yang beralamat di Batoh, Kota Banda Aceh, Provinsi Aceh, Indonesia.

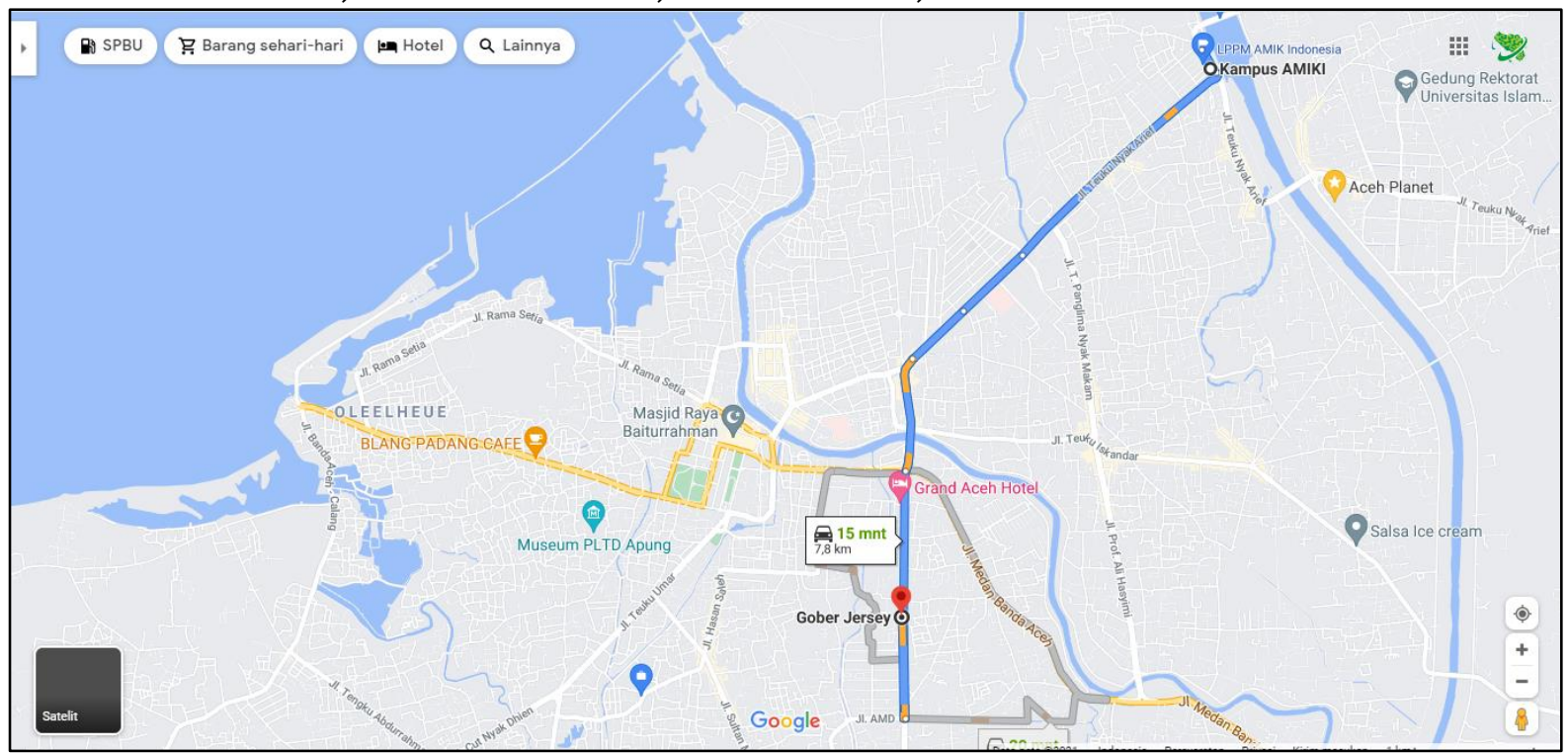

Gambar 1. Map Lokasi Kegiatan

\section{Hasil}

a. Kegiatan Persiapan

Adapun hasil dari kegiatan ini terdiri dari kegiatan persiapan yang dimulai dari wawancara dan diskusi dimana sesuai dengan metode tahapan yang direncanakan yaitu Presentasi dan Diskusi Sharing Pengalaman. Pada tahap ini dihasilkan sebuah aplikasi yang dibangun sesuai dengan kendala yang dihadapi usaha "Gober Indo" pada proses manajemen stok barang. Kegiatan ini berlangsung selama 2 (dua) bulan 


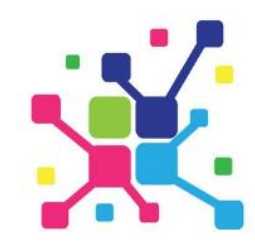

A J A D

Jurnal Pengabdian kepada Masyarakat

Vol. 1, No. 1, May, 2021, pp. 9-16 DOI : https://doi.org/10.35870/ajad.v1i1.3

dimana proses pembuatan aplikasi memerlukan waktu yang lama. Pada aplikasi yang dibangun terdiri dari beberapa modul/ menu yaitu;

1) New Order

Merupakan halaman yang memuat semua informasi maupun transaksi penjualan maupun pembelian yang dilakukan.

2) Order List

Merupakan halaman yang menampilkan informasi transaksi yang dilakukan

3) Report

Memuat informasi dalam bentuk laporan baik laporan barang, penjualan, pembelian, transaksi, invoice, custumer, product, dan pengguna aplikasi.

4) Charts

Memuat informasi dalam bentuk grafik baik pada periode harian, mingguan, dan bulanan berupa grafik barang, penjualan, pembelian, transaksi, invoice, custumer, product, dan pengguna aplikasi

5) Stock Control

Memuat informasi terkait bahan yang tersedia dan juga produk yang tersisa dari penjualan.

Berikut tampilan aplikasi Management Stock Control yang dihasilkan.

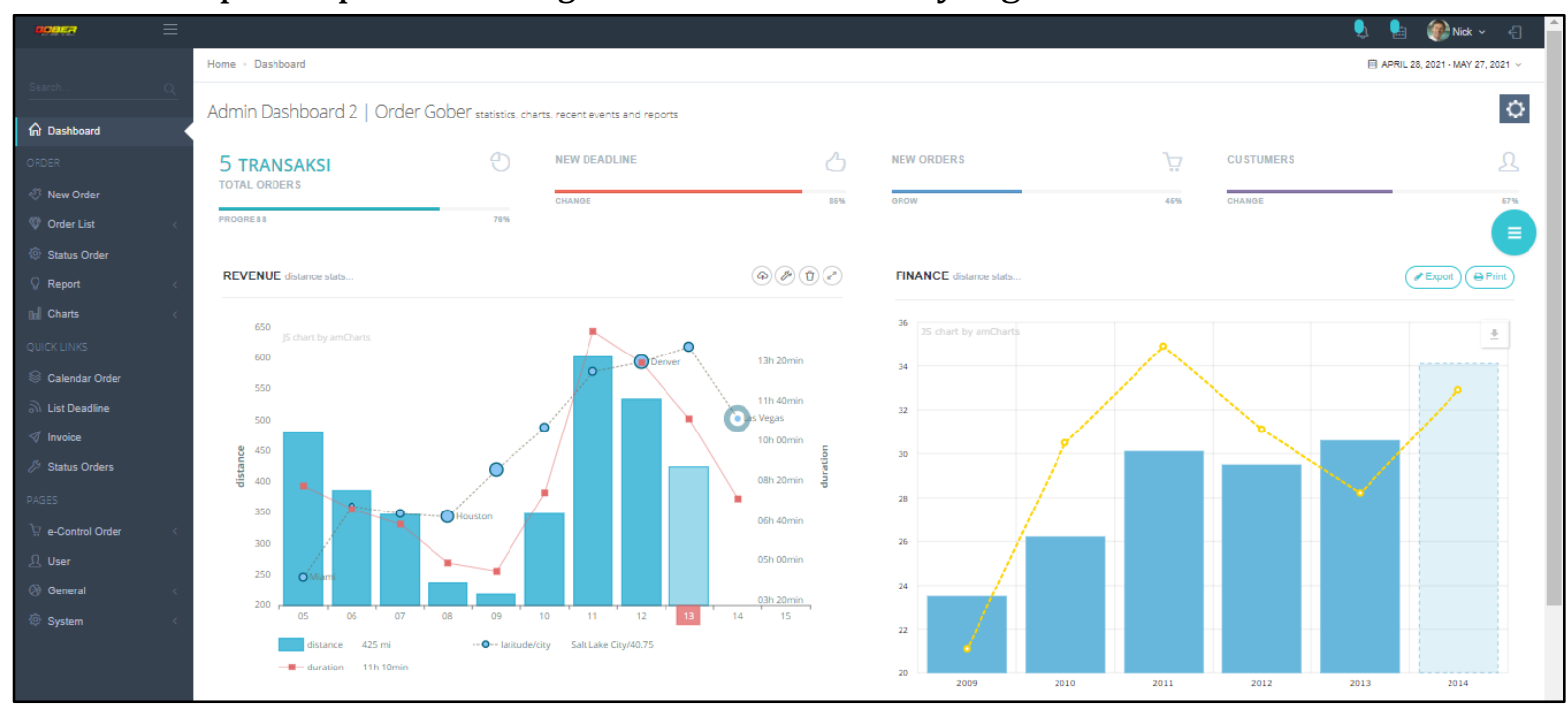

Gambar 2. Halaman Awal Aplikasi 


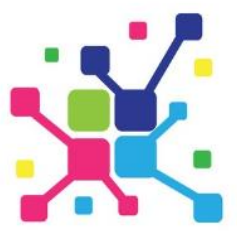

A J A D

Jurnal Pengabdian kepada Masyarakat

Vol. 1, No. 1, May, 2021, pp. 9-16

DOI : https://doi.org/10.35870/ajad.v1i1.3

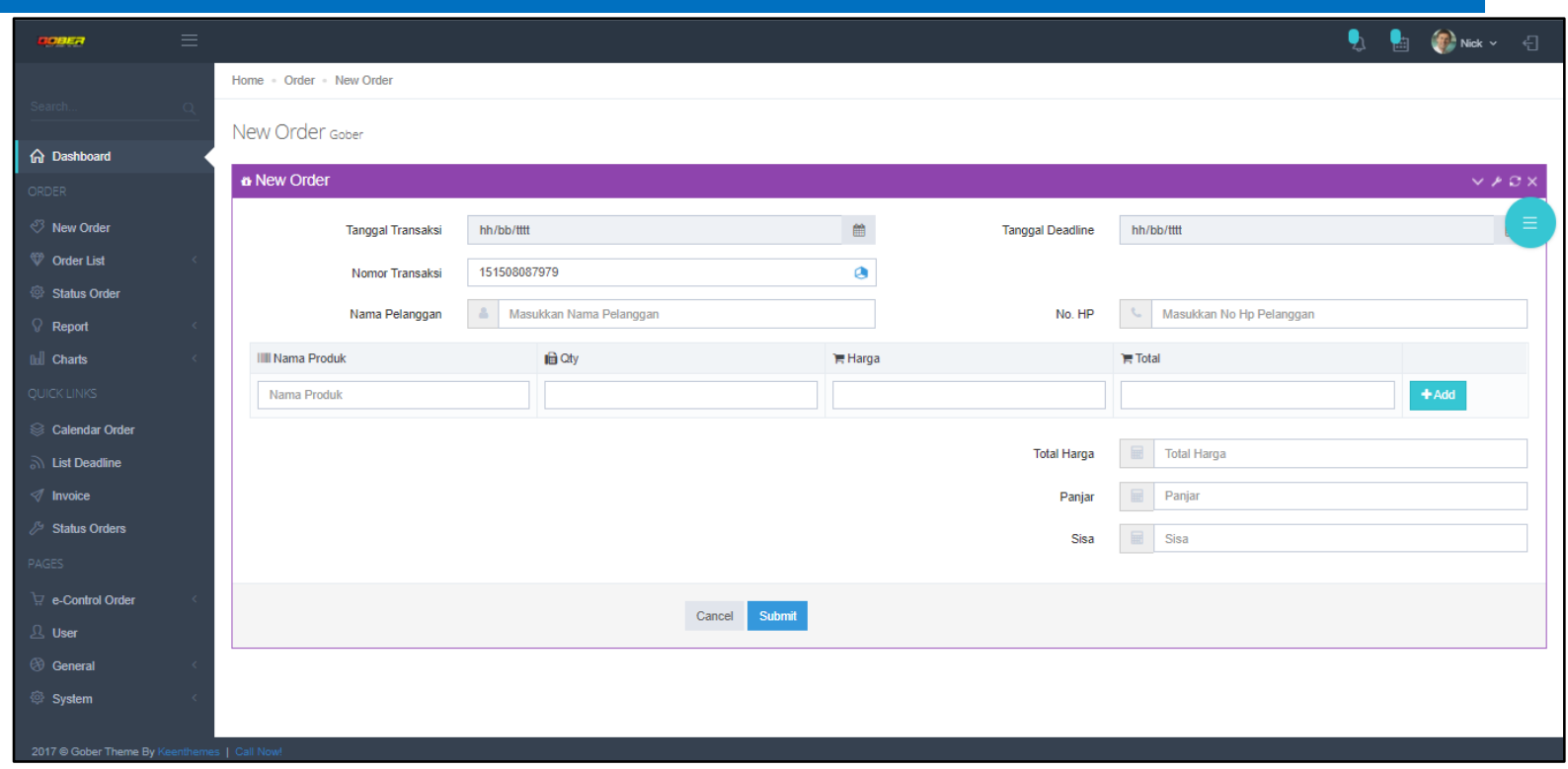

Gambar 3. Halaman Order / Transaksi

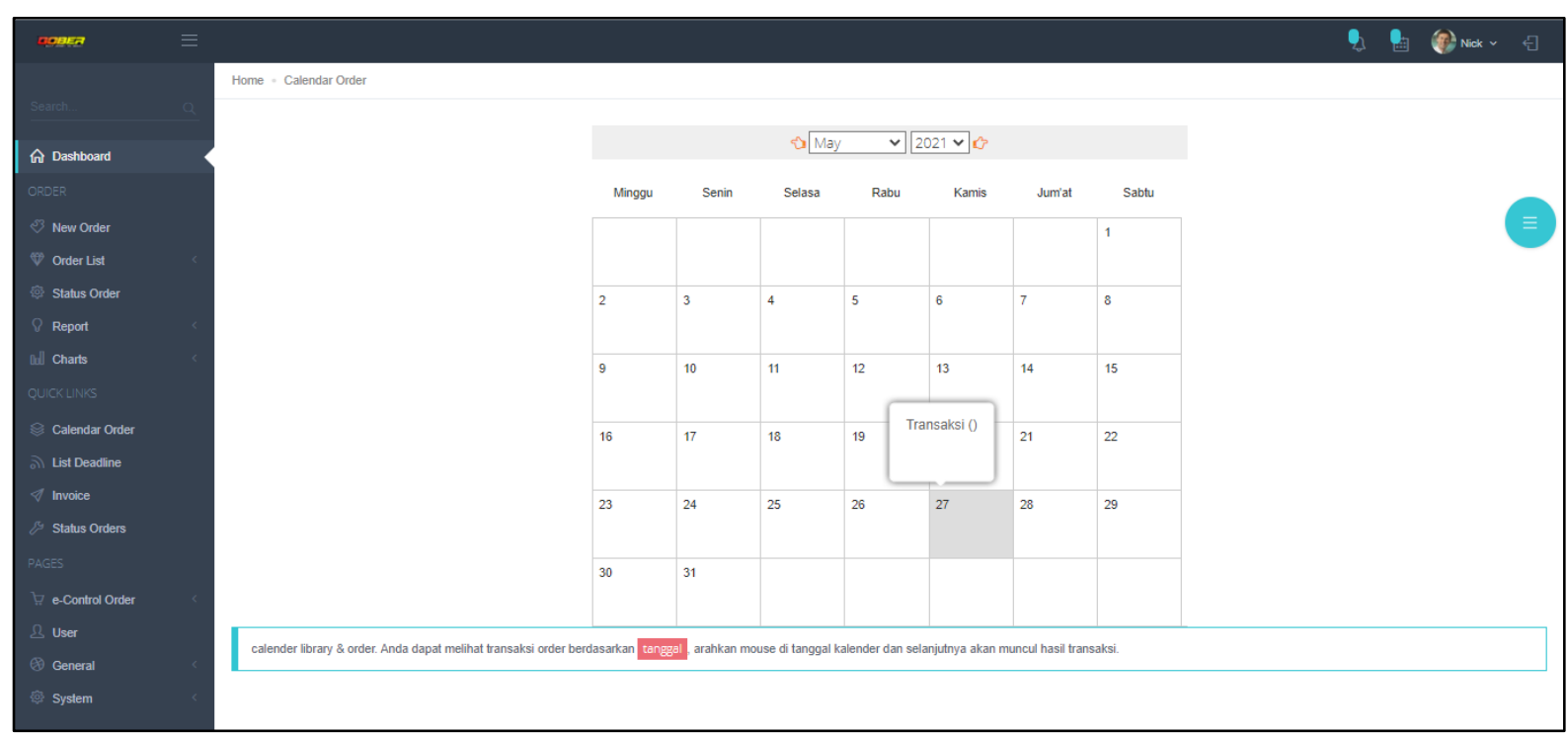

Gambar 4. Halaman Preview Order/ Transaksi Kalender 


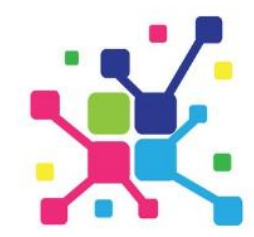

A J A D

Jurnal Pengabdian kepada Masyarakat

Vol. 1, No. 1, May, 2021, pp. 9-16

DOI : https://doi.org/10.35870/ajad.v1i1.3

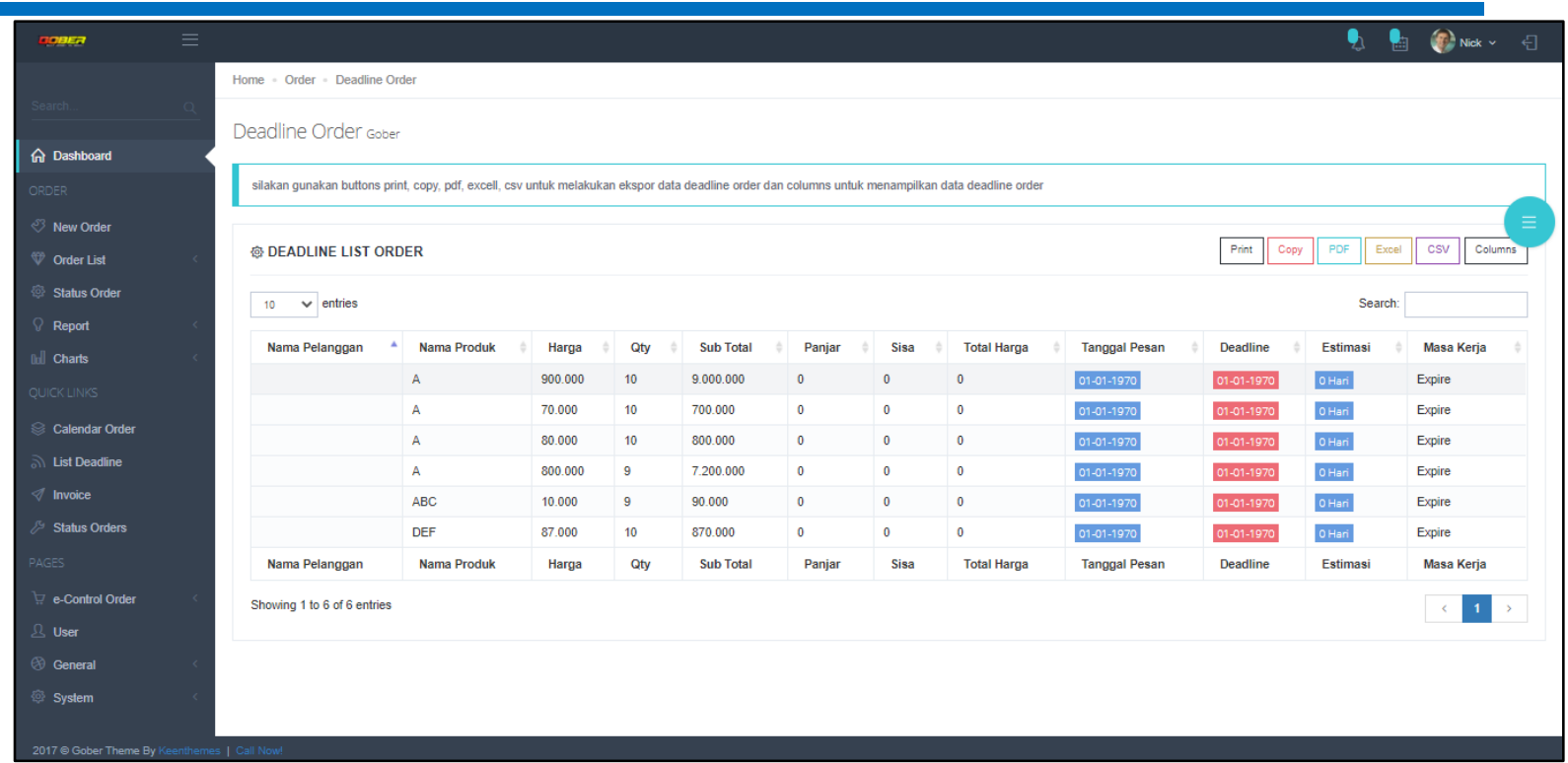

Gambar 5. Halaman Order dan Stock

b. Pelatihan (Training Users)

Pada tahapan ini diberikan pelatihan dan instruksi penggunaan aplikasi kepada mitra, kegiatan ini juga dibahas materi; 1) Dasar-dasar persediaan barang, 2) Strategi Peneyediaan Barang, 3) Pengendalian Persediaan, 4) Pengendalian Keperluan Overhaul, dan 5) Persediaan pengaman dan perhitungan Min Max. Praktek dilakukan dengan memperagakan contoh-contoh kasus, menunjukkan cara mamasukkan data yang diperlukan untuk aplikasi dan sebagainya. Kegiatan ini berlangsung selama 1 bulan yaitu awal bulan Februari tahun 2020.

c. Pendampingan lebih lanjut penggunaan aplikasi

Pada tahap akhir dilakukan pada bulan Maret 2020, dimana dilakukan wawancara dan pengamatan dari penggunaan aplikasi oleh pihak mitra.

\section{Kesimpulan}

Berdasarkan laporan kegiatan yang telah dipaparkan, berikut ini beberapa kesimpulan yang bisa dihasilkan.

1. Pembuatan aplikasi Management Stock Control berbasis web telah berhasil dibangun yang terdiri dari modul; 1) New Order, 2) Order List, 3) Report, 4) Charts, dan 5) Stock Control.

2. Kegiatan pendampingan dan pelatihan penggunaan Aplikasi Management Stock Control telah sesuai dan dapat membantu mitra.

3. Kegiatan IbM diikuti dengan sangat antusias terlihat banyaknya anggota dan pemilik dalam mengikuti pelatihan tersebut.

4. Kegiatan pendampingan Aplikasi Management Stock Control diharapkan dapat berlanjut dengan pengembangan keuangan usaha mitra. 


\section{Daftar Referensi}

[1] Zellweger, T., 2017. Managing the family business: Theory and practice. Edward Elgar Publishing.

[2] Harmon, P., 2019. Business process change: a business process management guide for managers and process professionals. Morgan Kaufmann.

[3] Crane, A., Matten, D., Glozer, S. and Spence, L., 2019. Business ethics: Managing corporate citizenship and sustainability in the age of globalization. Oxford University Press, USA.

[4] Pourhejazy, P., 2020. Destruction Decisions for Managing Excess Inventory in ECommerce Logistics. Sustainability, 12(20), p.8365.

[5] Derhami, S., Smith, J.S. and Gue, K.R., 2020. A simulation-based optimization approach to design optimal layouts for block stacking warehouses. International Journal of Production Economics, 223, p.107525.

[6] Donner, M., Gohier, R. and de Vries, H., 2020. A new circular business model typology for creating value from agro-waste. Science of the Total Environment, 716, p.137065.

[7] Heikkurinen, P., Young, C.W. and Morgan, E., 2019. Business for sustainable change: Extending eco-efficiency and eco-sufficiency strategies to consumers. Journal of Cleaner Production, 218, pp.656-664.

[8] Kaydos, W., 2020. Operational performance measurement: increasing total productivity. CRC press.

[9] Wali, M., 2019. Application Optimizing the Placement of Safety Stocks Using the Max-Min Method for Printing Companies. International Journal of Research and Review, 6(2), p.203-210.

[10] Nascimento, D.L.M., Alencastro, V., Quelhas, O.L.G., Caiado, R.G.G., Garza-Reyes, J.A., Rocha-Lona, L. and Tortorella, G., 2019. Exploring Industry 4.0 technologies to enable circular economy practices in a manufacturing context. Journal of Manufacturing Technology Management.

[11] Iqbal, T., Aprizal, D. and Wali, M., 2017. Aplikasi Manajemen Persediaan Barang Berbasis Economic Order Quantity (EOQ). Jurnal JTIK (Jurnal Teknologi Informasi dan Komunikasi), 1(1), pp.48-60.

[12] Rachmawati, R., 2011. Peranan bauran pemasaran (marketing mix) terhadap peningkatan penjualan (sebuah kajian terhadap bisnis restoran). Jurnal Kompetensi Teknik, 2(2). 
[13] Hayati, E.N., 2014. Supply Chain Management (SCM) dan Logistic Management. Jurnal Ilmiah Dinamika Teknik.

[14] Zulkarnaen, W., Fitriani, I.D. and Yuningsih, N., 2020. Pengembangan Supply Chain Management Dalam Pengelolaan Distribusi Logistik Pemilu Yang Lebih Tepat Jenis, Tepat Jumlah Dan Tepat Waktu Berbasis Human Resources Competency Development Di KPU Jawa Barat. Jurnal Ilmiah MEA (Manajemen, Ekonomi, \& Akuntansi), 4(2), pp.222-243.

[15] Sulaiman, F. and Nanda, N., 2018. Pengendalian Persediaan Bahan Baku dengan Menggunakan Metode Eoq pada Ud. Adi Mabel. Jurnal Teknovasi: Jurnal Teknik dan Inovasi, 2(1), pp.1-11.

[16] HARIRI, H., 2005. Perencanaan Kebutuhan Material (MRP). Jurnal Mekanikal Teknik Mesin FTUP, 1(2).

[17] Aristiyanto, F., Putri, N.T. and Adi, A.H.B., 2016. Usulan aplikasi metode material requirement planning (MRP) dalam perencanaan kebutuhan firebrick PT. Semen Padang. Jurnal Optimasi Sistem Industri, 15(2), pp.217-226.

[18] Winanda NI, A., 2017. Efisiensi dan Efektivitas Pengelolaan Bahan Baku pada PT. Eastern Pearl Flour MILSS Makassar (Doctoral dissertation, Universitas Islam Negeri Alauddin Makassar). 